\title{
DERECHOS DE LAS VÍCTIMAS MENORES DE EDAD EN LOS CASOS DE VIOLACIÓN BAJO EL SISTEMA PENAL ACUSATORIO
}

Andrés Antonio Alarcón Lora María José Anaya Luna

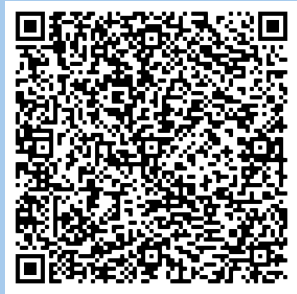




\title{
DEREGHOS DE LAS VÍCTIMAS MENORES DE EDAD EN LOS GASOS DE VIOLAGIÓN BAJO EL SISTEMA PENAL AGUSATORIO
}

\author{
Andrés Antonio Alarcón Lora', María José Anaya Luna²
}

\section{Palabras clave \\ Protección, proceso penal, ley, jurisprudencia, menores de edad.}

\section{RESUMEN}

En el presente escrito se realizó un análisis tanto normativo como jurisprudencial sobre los derechos de las víctimas bajo el proceso penal acusatorio, con el objetivo de identificar y analizar cuáles son las formas de garantizarlos y la efectividad de estos. Partiendo de la relevancia de que estas personas son de especial protección dentro de nuestro ordenamiento jurídico, al presentarse casos dentro de nuestra sociedad en que se podrían ver vulnerados.

1. Docente Investigador de la Facultad de Derecho y Ciencias Políticas de la Universidad de Cartagena, Líder del Semillero de Investigación "Reorganización Empresarial" adscrito al Grupo Derecho del Trabajo y Seguridad Social, Jefe Departamento de Postgrados y Educación Continua, Doctor en Ciencias de la Educación, Universidad de Cartagena - RUDE Colombia. Magister en Derecho Universidad del Norte, Especialista en Derecho Comercial Universidad Externado de Colombia. Email: analarcon28@gmail.com Orcid: https://orcid.org/0000-0003-1297-7049

2. Estudiante de séptimo semestre del Programa de Derecho de la Universidad de Cartagena. Perteneciente al semillero "Reorganización Empresarial", adscrito al Grupo de Investigación de Derecho del Trabajo y Seguridad Social bajo la dirección de Josefina Quintero Lyons. Email: Marijoanlu98@hotmail.com Orcid: https://orcid.org/0000-0003-1050-1039 


\section{Key words}

Protection, criminal procedure, laws, jurisprudence, underage.

\section{Abstract}

In the present article, it is an analysis from the law and the jurisprudence about the rights of the victims in the criminal process, with the objective of identifying and analyzing the ways of an effective guarantee of them. Starting from the relevance of the special protection of these people in our laws, are occurred some cases in our society when they could be violated. 


\section{INTRODUGGIÓN}

Cuando nos encontramos con la noticia criminal, se advierte la presencia de distintos actores sobre los cuales recae la responsabilidad objeto de las consecuencias del ilícito, que deben responder con la pena impuesta por su actuación delictuosa y la victima sobre la que pesa un daño producido a través del actuar de los responsables. En un sistema penal amparado por una constitución garantista como la colombiana, no solo se debe contemplar la pena en miras del respeto a los derechos de las personas, sino, la debida protección de derechos y el resarcimiento integral a las víctimas menores por el daño causado de tal forma que satisfagan las necesidades personales que surgen del injusto penal.

\section{El Estado debe propender por una} política de protección y resarcimiento efectivo de los derechos de los menores al ser de mayor interés tanto a nivel nacional como internacional por la circunstancia de debilidad manifiesta que los ampara, la víctima ha adquirido un papel importante en el proceso adversarial. Así pues, se busca una protección jurídica de esta en el proceso, teniendo en cuenta que muchas ocasiones la escasa diligencia de los actores en el curso del proceso. Para ser efectivos estos derechos pueden traer que el afectado desista o se retracte de sus declaraciones, el daño se perpetúe, exista impunidad, a veces se obvia por parte de los distintos actores dentro de un proceso, el procedimiento para conseguir de forma efectiva la garantía de los derechos e intereses, lo cual es objeto de esta investigación.
El desarrollo de la presente investigación tiene como presente el papel preponderante que tiene la victima dentro de un proceso, $y$ aún más si se trata de un menor de edad en los casos de violencia sexual contra su persona y la importancia que tiene la protección de sus derechos en la sociedad que vigila sobre la efectiva protección de estos. Por lo cual es importante el determinar las herramientas con las que cuenta para velar por el amparo de sus derechos, por lo tanto primeramente resulta conveniente definir el concepto de victima tanto en la ley como en la jurisprudencia, su papel dentro de un proceso, las facultades de la fiscalía por mandato constitucional para la defensa de estos intereses, establecer mecanismos para la efectiva defensa de sus garantías, examinando las leyes, la jurisprudencia al respecto en este tipo de casos.

Para eso cabría preguntar ¿se aplican efectivamente las facultades y garantías y se protegen los derechos que contempla la ley para con las victimas menores de edad en los casos de violación?, apreciando el contexto social se presentan casos en donde la lentitud de los procesos puede agravar sus condiciones, causar más perjuicio, conllevar a la impunidad, discriminar a la víctima, llegando a ser una situación de especial importancia en un estado social de derecho que consagra la constitución. ¿Qué facultades tiene la víctima menor de edad para hacer valer sus derechos en los casos de violación?, a raíz de tantas cuestiones la presente investigación se plantea como pregunta problema la siguiente: ¿en el proceso de la ley 906 de 2004 se garantizan efectivamente los Derechos fundamentales de los menores de edad en los casos de violación?, para darle cumplimiento a la pregunta 
problema no trazamos como objetivo general, Estudiar de forma exhaustiva el proceso de la ley 906 y si esta efectivamente garantiza los derechos fundamentales de los menores en los casos de vulneración de los mismos, así mismo para materializar el objetivo general propuesto se diseñaron tres objetivos específico, establecer mediante estudio de la norma y jurisprudencia que mecanismos tienen las víctimas para las garantías de sus intereses en el curso de la investigación penal, establecer si el Estado ha propiciado una política para la protección de los Derechos Humanos de los menores identificando que medidas ha adoptado para investigar, castigar y reparar al menor de edad de un delito sexual.

\section{Metodología}

El desarrollo de esta ponencia se desarrolla desde punto de vista jurídico, se enfoca desde el punto de vista dogmático, con el objetivo de analizar el marco normativo y jurisprudencial en el tratamiento de victimas menores de edad, sus derechos y facultades para proteger sus intereses, destacando aspectos fundamentales a lo largo del desarrollo de un proceso penal derivado de la comisión del delito que afecte contra la libertad sexual de la infancia. La técnica de recolección de información es la del análisis de información de carácter secundario.

\section{LA Víctima}

El origen de esta palabra tiene connotaciones religiosas, y a lo largo de la historia ha ido evolucionando dependiendo la forma de gobierno tratando de ser clasificada bajo distintas etiquetas dependiendo del ámbito social en que se encuentre, es necesario precisar que no necesariamente una víctima es la que sufre un daño directo e inmediato porque pueden afectar no a una persona determinada sino a un colectivo, cabe destacar que esta figura es importante en las conductas delictivas que se encuentra en el opuesto de la relación con el victimario encontrándose una clara diferenciación entre estos. Se encuentra configurada esta figura en la Constitución de 1991, artículo 250 numeral 6 en donde señala como un deber de la Fiscalía "disponer del restablecimiento del derecho y los afectados por el delito". Seguidamente su numeral 7 les otorga el carácter de intervinientes siendo una capacidad especial ya que pueden ejecutar las actividades tendientes a defender sus adquiere las mismas herramientas y relevancia que las partes.

Antes de la ley 906 de 2004 los derechos del sujeto pasivo se consagraban y regulaban a través de distintas jurisprudencias de la Corte Constitucional en donde esta figura estaba consagrada como una parte civil dentro del proceso penal, los derechos del sujeto pasivo de un delito son la verdad, justicia y reparación, que se instauraron desde el 2002 en el Acto legislativo 03 y fue desarrollado ampliamente por la Corte mereciendo la pena subrayar la sentencia c- 228 de 2002 que marca un antes y después en el tratamiento de la víctima durante el proceso, se la define como "la persona respecto a la cual se materializa el delito, se diferencia del termino perjudicando en que este comprende un alcance mucho mayor, es decir todo aquel que resulte afectado directamente por el delito". Su intervención siguiendo a la Corte dentro de este proceso no puede reducirse solamente a pretensiones de carácter pecuniario, si no que va más allá y abarca todos los entornos 
que rodean a la víctima. Ya en el 2004 cuando surge la ley 906, en su artículo 132 consagra: "Se entiende por victimas las personas naturales o jurídicas y demás sujetos de derecho que individual o colectivamente hayan sufrido algún daño como consecuencia del injusto".

A partir de este punto se manifiesta la Corte Constitucional en otra serie de jurisprudencias respecto a la consagración de la víctima en el proceso penal destacando la C-370 de 2006 como "la persona que ha sufrido un daño real, concreto y especifico, cualquiera que sea la naturaleza de éste o del delito que lo ocasiona" agrega también que el grado de consanguineidad deja de ser el factor más importante para definir a las personas legitimadas para intervenir en el proceso penal. Por su parte la sentencia C-209 de 2007 consagra los derechos de las víctimas al determinar:

Que quien ostenta los derechos de verdad justicia y reparación como consecuencia de haber sido perjudicados por un delito que genere un daño real, concreto y especifico no necesariamente patrimonial, esto se ha sostenido tanto en procesos penales como en otras jurisdicciones. La victima a su vez tiene el derecho a acceder a la administración de justicia, a la reparación integral, así como a obtener medidas judiciales de protección, sin perjuicio de poder acudir ante la jurisdicción civil ordinaria para obtener la reparación del daño ocasionado con el delito.

En reciente pronunciamientos como en la sentencia T-347/13 los derechos de las víctimas se reconocen al punto en que sus intereses dentro del proceso penal influencian en los fines del proceso que deben apuntar al restablecimiento de la paz social.

\section{Justicia Restaurativa}

Dentro de la ley 906/04 se propende hacia una justicia restaurativa siguiendo los lineamientos internacionales, que no solo abarca pretensiones monetarias, también reparaciones simbólicas, tratamientos psicológicos, busca que la reparación sea acorde a los perjuicios causados, por esta razón consagra distintos mecanismos como la mediación, conciliación procesal y el incidente de reparación integral. En su artículo 518 la definiría como:

Se entenderá por programa de justicia restaurativa todo proceso en el que la víctima y el imputado, acusado o sentenciado participan conjuntamente de forma activa en la resolución de cuestiones derivadas del delito en busca de un resultado restaurativo, con o sin la participación de un facilitador.

Se entiende por resultado restaurativo, el acuerdo encaminado a atender las necesidades y responsabilidades individuales y colectivas de las partes y a lograr la reintegración de la víctima y del infractor en la comunidad en busca de la reparación, la restitución y el servicio a la comunidad. En búsqueda de una forma más efectiva de retribución entre las partes de manera alterna al proceso penal que busca la restauración de la dignidad de la víctima, reincorporar al sujeto activo dentro de la sociedad, reparar el daño; se pronuncia al respecto la Corte en sentencia C-979 de 2005: 
La justicia restaurativa se presenta como un modelo alternativo de enfrentamiento de la criminalidad, que sustituye la idea tradicional de retribución o castigo, por una visión que rescata la importancia que tiene para la sociedad la reconstrucción de las relaciones entre víctima y victimario. $\mathrm{El}$ centro de gravedad del derecho penal ya no lo constituiría una especie de consideración a la víctima y al daño que le fue inferido.

A su vez la justicia restaurativa implica no solo la resocialización, sino la condena al delincuente siguiendo a Ketarina Bach "la afrontación del daño por parte de la víctima y la racionalización de la conducta preventiva para la sociedad."

\section{Mediación}

Consagrada en el artículo 523 del código de procedimiento penal la podríamos definir como el intercambio de opiniones frente un afectado y un ofensor ante un $3^{\circ}$ neutral en lo referente a la restauración, reparación, restitución de los perjuicios; realización o abstención de determinada conducta; prestación de servicios a la comunidad; o el ofrecimiento de disculpas.

Debe ser de libre concurrencia de las partes, y la pueden pedir ambas ante fiscal, juez de control de garantías o juez de conocimiento dependiendo de en qué etapa del proceso se encuentra, el termino para pedirla es desde la formulación de la imputación hasta antes de la audiencia de juicio oral, aplicable tanto a delitos de carácter querellables como los que se persiguen de oficio que su pena no exceda los 5 años. Su uso excluye al incidente de reparación integral ya que ambos apuntan a un mismo objetivo.

\section{Conciliación}

Se aplica en el ámbito de los delitos que son investigados a petición del agraviado como un requisito de procedibilidad. Es un acuerdo que realiza tanto la víctima como el victimario para superar los conflictos a través de unos compromisos que adquieren las partes. La conciliación puede ser antes del proceso cuando son celebradas antes de la audiencia de formulación de la imputación y procesal cuando es posterior a esta (Sentencia C-975/2005).

Puede surtirse ante fiscal y si se llegare a un acuerdo se archiva en caso contrario se inicia la acción penal. La conciliación realizada dentro del incidente de reparación integral puede considerarse como un mecanismo de la justicia restaurativa. Este incidente propicio a una conciliación entre las partes y en caso tal de que fracase tal conciliación el juez decide de plano según las pruebas presentadas ambas formas de terminación del incidente se incluirán en la sentencia condenatoria (Sentencia C-975/2005). Siguiendo lo planteado en la sentencia C-228 de 2002 se señalan los 3 tres derechos fundamentales de una víctima en el proceso que son el de verdad, justicia y reparación.

\section{Derecho a LA Verdad}

En base a esta jurisprudencia puede definirse como la posibilidad de conocer lo que sucedió y buscar una coincidencia entre la verdad procesal y la verdad real. Y lo amplía la sentencia C-454 de 2006 al derecho a la verdad, a saber y el deber de recordar, de lo contrario se afectaría la dignidad humana, 
existiendo así un claro vínculo entre el respeto a la dignidad humana, de la víctima y su memoria.

\section{Derecho a la justicia}

Esta misma sentencia (c-454/ 06) nos señala el derecho a la justicia como lo que congloba el deber del estado e investigar y sancionar adecuadamente a los autores y partícipes de los delitos, el derecho de las víctimas a un recurso judicial efectivo y el deber de respetar en todos los juicios las reglas del debido proceso. Dentro del ámbito de este derecho encontramos inmerso otros, consagrados en distintos instrumentos internacionales protectores de los derechos de las personas como la Declaración Universal de Derechos Humanos que comprende el derecho a un recurso judicial efectivo, al debido proceso cuando existe un tribunal competente, la igualdad, la imparcialidad, la efectividad de los derechos.

\section{Derecho a la RePaRAGión}

Siguiendo lo expresado por la corte en la sentencia C-454 de 2006 lo define como las medidas individuales relativas al derecho de restitución, indemnización, rehabilitación, satisfacción y garantía de no repetición. Su fundamento político tiene como punto de partida el reconocimiento positivo de la disposición del autor en asunción de su responsabilidad ante las víctimas y ante la sociedad (Sampedro, 2014). Según la ley de víctimas entendemos por restitución la devolución de la víctima a su estado anterior antes de la comisión del delito, por indemnización lograr el resarcimiento de los daños ocasionados por el ilícito, la satisfacción será entendida como las medidas simbólicas para compensar el daño moral causado, la rehabilitación como la prestación de atención médica necesaria.

\section{GARANTÍAS DE VÍCTIMAS MENORES EN GASOS DE VIOLAGIÓN POR PARTE DE LAS INSTITUGIONES ESTATALES Y EN EL PROGESO}

$\mathrm{Al}$ ser un sector de la población con debilidad manifiesta que no se encuentra en igualdad de condiciones que los demás, bajo la constitución de 1991 el Estado puede implementar medidas orientadas para beneficiar a determinado grupo de personas eliminando así algunas barreras existentes. Se hace necesario y urgente las medidas necesarias para salvaguardar los intereses de estas personas ya que la afectación de sus derechos según lo conceptuado por el ICBF no solo va desde el punto de vista físico, sexual y psicológico, sino también refiere al potencial daño en el desarrollo integral y la construcción de la identidad de niño, niña y adolescente.

La ley 1146 de 2007 consagra una definición de violencia sexual en su artículo 2 como:

$$
\begin{aligned}
& \text { Todo acto o comportamiento de tipo } \\
& \text { sexual ejercido sobre un niño, niña } \\
& \text { o adolescente, utilizando la fuerza o } \\
& \text { cualquier forma de coerción física, } \\
& \text { psicológica o emocional aprovechando } \\
& \text { las condiciones de indefensión, de } \\
& \text { desigualdad y las relaciones de poder } \\
& \text { existentes entre víctima y agresor. }
\end{aligned}
$$

En nuestra legislación penal encontramos tipificados delitos que atentan contra la libertad sexual de los menores, creados en la base de la especial protección y preponderancia de sus derechos por encima 
de los demás. El Código de Infancia y

Adolescencia en sus artículos 192 y 193 se hace referencia cuando el afectado sea menor resulta importante de tener en cuenta su dignidad, intimidad y demás derechos consagrados, su opinión, su calidad de niños, se les dé respeto. La misma ley de procedimiento penal consagra los distintos medios de conocimiento para probar la autoría, la existencia de injusto, las circunstancias e tiempo, modo y lugar. Medios como "la prueba pericial, la prueba documental, la prueba de inspección, los elementos materiales probatorios, evidencia física o cualquier otro medio técnico o científico que no viole el ordenamiento jurídico."

Para evitar la impunidad la jurisprudencia y la ley reglamentan casos en donde la actuación de la víctima es válida en aras de evitar la impunidad del perpetrador.

\section{Declaración de menores}

Se hace necesarias, e importantes en muchos casos porque puede que la evidencia física sea insuficiente, para una mejor apreciación de lo ocurrido, una mayor recolección de información sobre los hechos, una determinación de los posibles autores del injusto, logre formarse una visión de los hechos, de las personas que participaron, de las posibles motivaciones. En el caso de entrevista que realiza el médico forense al menor, se amplía también a los padres o representantes y contará con la autorización debida tanto para la entrevista como para el examen médico legal, se pueden utilizar dibujos, figuras y requiere que sea realizada por un especialista, se apreciará la entrevista de acuerdo al grado de capacidad de entendimiento y el manejo del lenguaje.

El testimonio de menores a su vez es aceptado dentro del proceso penal, no están obligados a prestar juramento al momento de declarar y deben estar acompañados por sus padres o parientes mayores de edad. El juez para valorarlo se basará en las reglas de la sana crítica y en los criterios de la ley penal para valorar el testimonio, para lograr la protección del interés superior la jurisprudencia de la Corte Suprema ha manifestado varias veces la flexibilización de las pruebas generales de la prueba testimonial "lo que se traduce en la posibilidad de incorporar como pruebas sus declaraciones anteriores, así el niño comparezca en el juicio oral" (SP2709-2018).

Continúa la Corte en el caso de imposibilidad de contradicción de la parte contra quien se aduce la prueba, esta tomará el carácter de prueba de referencia. Siguiendo esta línea el testimonio de menores no puede tener una valoración parcial ni prejuiciosa dependiendo de la edad del declarante sus dichos se evaluarán en conjunto con las otras pruebas y se les otorgará el valor debido. Dentro de este medio de conocimiento cabe la retractación que consiste en el cambio parcial o total que hace una persona sobre la versión de los hechos realizada anteriormente, y se valorará de forma comparativa ambos testimonios ya que esta figura no destruye de forma completa el testimonio, ni considera como única verdad lo expresado posteriormente. En el caso de las investigaciones de delitos sexuales es necesaria la prueba pericial donde es imperativa la dignidad humana, no se le privará de su 
consentimiento para este tipo de casos y el juez de control de garantías decidirá sobre la práctica o no prevaleciendo la decisión de la víctima.

En el caso de los menores para establecer posibles secuelas consecuencia del injusto se debe remitir al psiquiatra o psicólogo, su grado de precisión y credibilidad. En algunos casos la falta de formación de los expertos con llevan a una victimización del afectado, lo cohíben de expresarse libremente, pueda sentir culpa, sentir miedo o vergüenza, haciendo así necesario la utilización de especialistas adecuados para evitar una revictimización, lograr confianza en el menor para denunciar, evitar que las consecuencias se perpetúen en el tiempo. Para garantizar los derechos de los menores el ministerio público se encuentra facultado para solicitar medidas cautelares que protejan a estos.

A lo largo del proceso penal encontramos plasmados los tres derechos fundamentales de la víctima que son verdad, justicia y reparación. Empezando por la etapa de indagación en donde tiene derecho a la atención, protección inmediata mediante los distintos órganos estatales como la Fiscalía, a que se le comuniquen los derechos, el estado del proceso, pueden actuar sin necesidad de abogado excepto cuando inicia la etapa de la audiencia preparatoria. Pueden a su vez acorde con la sentencia C-454 de 2006 acceder al expediente del proceso llevado por la fiscalía. La victima también puede solicitar la práctica de pruebas de forma conjunta con las partes, esto según la jurisprudencia no afecta la estructura del proceso, pueden presentar recursos contra las decisiones que atenten contra la sentencia, la víctima puede oponerse a los preacuerdos realizados por las partes.

En la etapa de investigación las victimas pueden solicitar medidas de aseguramiento o medidas cautelares ante juez de control de garantías en base a la sentencia c- $297 \mathrm{de}$ 2007 esta facultad no afecta la igualdad, ni genera un desequilibrio. En la audiencia de formulación de la acusación esta sentencia extiende sus facultades al permitirle a la víctima realizar observaciones, pronunciarse sobre nulidades, en la misma forma que las partes. Con el fin de que se materialicen sus derechos se les permite a las víctimas en la misma forma que las partes pedir pruebas, solicitar descubrimiento de elementos materiales probatorios y evidencia física. En el caso de la audiencia de juicio oral la víctima no puede participar en el curso de ella, ya que sus intereses se encuentran protegidos por la Fiscalía al presentar la teoría del caso y realizar el descubrimiento probatorio, solamente el representante de víctimas puede presentar alegatos de conclusión acorde a lo dicho por la fiscalía.

\section{Conclusiones}

Con la entrada de la nueva constitución se procuró la defensa de los Derechos Humanos, principalmente la dignidad que es la base de donde surgen los demás derechos, la víctima asume un papel importante dentro del proceso y se puede observar que actualmente las leyes se vuelven más garantistas de los intereses de estas dentro de la acción penal. Sus intereses ya no solo se limitan a un resarcimiento pecuniario, sino que abarca el aspecto moral y psicológico para evitar una ruptura de la 
sociedad, donde el Estado adquiere un gran compromiso al velar por estas garantías, la Corte por su parte entra a regular los distintos mecanismos con el que cuentan las partes en vista de un vacío en la legislación.

Se da una especial protección por parte de las distintas entidades estatales a las víctimas menores de edad, al ser personas con una debilidad manifiesta y que sus intereses adquieren un carácter superior con respecto a los demás derechos. Encontramos que el Estado en busca de propender por la efectiva protección de estos, sus entidades estatales establecieron un protocolo especial para proseguir cuando se cometen este tipo de delitos, propendiendo que esta debilidad sea subsanada para que adquiera condiciones de igualdad con el resto de grupos sociales. Por su parte dentro de las instituciones es necesario contar con equipo especializado para evitar que dentro de la misma diligencia se evite una revictimización agravando así la condición psicológica del afectado, para prevenir este tipo de situaciones el programa metodológico tanto del ICBF abarca un programa interdisciplinario entre distintas entidades en aras de restablecer el derecho y permitirle al menor una adecuada educación y crecimiento para que pueda desarrollarse como una persona normal dentro de la sociedad.

Por su parte la Fiscalía en su programa para atender este tipo de situaciones, determina la forma en cómo deben ser llevados a cabos los distintos procedimientos para obtener elementos materiales probatorios y evidencia física, como deben llevarse a cabo las entrevistas, la práctica de exámenes periciales, la toma de muestra en base al respeto de la persona, la dignidad, en condiciones de higiene. A lo largo del proceso el afectado cuenta con distintos mecanismos para garantizar sus derechos fundamentales, evitando así la impunidad y la efectiva reparación de las secuelas producto de las consecuencias del injusto, considero finalmente que podría avanzarse aún en la protección de los derechos del sujeto pasivo, tener más garantías y distintos mecanismos que puedan hacer un efectivo cumplimiento de los derechos de las victimas consagrados en la jurisprudencia.

\section{REFERENGIAS}

Acosta, L. \& Medina, R. (2015). La víctima y su resarcimiento en los sistemas penales colombianos. Jurídicas CUC, 11(1), 3958. doi: http://dx.doi.org/10.17981/ juridcuc.11.1.2015.2

Amaris, C. (2011). Evolución Jurisprudencial de los derechos fundamentales de las víctimas en el sistema acusatorio colombiano. (Tesis para optar por el título de pregrado). Universidad de Cartagena, Cartagena.

Ardila, H. (2012). Los derechos de las víctimas: Estudio sobre los derechos sustantivos y procesales de las víctimas. Bogotá: Nueva Jurídica

Corte Constitucional (2002). Sentencia C-228/02

Corte Constitucional (2005). Sentencia C-979/05

Corte Constitucional (2006). Sentencia C-454/06

Corte Constitucional (2007). Sentencia C-209/07

Corte Constitucional (2007). Sentencia C-297/07

Corte Constitucional (2013). Sentencia T-347/13

Corte Constitucional (2014). Sentencia T-309/14

Corte Constitucional (2003). Sentencia T-554/03

Corte Suprema de Justicia (2018). Sentencia SP5290-201844564 
Corte Suprema de Justicia (2011). Radicado 34568

Delgado, C (2015). Derechos y facultades de las víctimas en el proceso penal colombiano a partir de la puesta en marcha de la ley 906/04. (Tesis de especialización). Universidad Militar Nueva Granada, Bogotá. Recuperada de https://repository.unimilitar.edu. co/bitstream/handle/10654/7656/DELGADOPATI $\%$ D1OCARLOSJULIO 2016. pdf;jsessionid $=65 \mathrm{E} 7 \mathrm{~F} 304 \mathrm{D} 033 \mathrm{C} 2 \mathrm{D} 67 \mathrm{AD}$ 27747FE54B160? sequence $=1$

Mejía, M. (2014). La participación de las víctimas en el sistema penal acusatorio colombiano, una perspectiva desde la jurisprudencia de la Corte Constitucional. (Tesis para optar por el título de pregrado). Universidad Católica de Colombia, Bogotá. Recuperado de https://repository.ucatolica.edu.co/bitstream/10983/1619/1/Monograf\%C3\%ADa $\% 20$ Mate $\% 20$ Mejia $\% 20$ Gallego $\% 20$ PDF $\% 2019 \% 20 \mathrm{de} \% 20$ marzo $\% 20 \mathrm{de}^{\%} \% 20$ 2014.pdf

Ortiz, D. y Castañeda, N. (2013). Dictámenes periciales en delitos sexuales dentro de la legislación colombiana. (Tesis de Maestría). Universidad Libre, Bogotá. Recuperado de https://repository.unilibre.edu.co/bitstream/ handle/10901/7535/OrtizFlorezDiegoAn dres2013.pdf?sequence $=1$

Peña, C. (2015). La retractación de los menores de edad y sus consecuencias en los procesos de delitos sexuales. (Tesis de especialización). Universidad Militar Nueva Granada, Bogotá. Recuperado de: https:// repository.unimilitar.edu.co/bitstream/ handle/10654/6655/LA\%20RETRACTACIO $\% 20$ DE $\% 20 L O S \% 20$ MENORES $\% 20$ DE $\% 20$ EDAD $\% 20 Y \% 20$ SUS $\% 20 \mathrm{CON}$ SECUENCIAS $\% 20 \mathrm{EN} \% 20 \mathrm{LOS} \% 20$ PROCESOS $\% 20 D E \% 20 D E L I T O S \% 20$ SEXUALES.pdf;jsessionid=2DC9B9FA75D28372F405E65883B2E87D? Sequence $=1$
Sampedro, J. (2014). Los Derechos Humanos de las víctimas Apuntes para la reformulación penal. Int. Law: Rev Colomb. Derecho Int. Ildi Colombia. (12) 353-372. Recuperado de http://www.scielo.org.co/pdf/ilrdi/n12/ n12a13.pdf 